\title{
Article \\ Rapid 3D-Imaging of Semiconductor Chips Using THz Time-of-Flight Technique
}

\author{
Jong Hyuk Yim ${ }^{1}$, Su-yeon Kim ${ }^{2}$, Yiseob Kim ${ }^{2}$, Suyoung Cho ${ }^{2}$, Jangsun Kim ${ }^{2}$ and Yeong Hwan Ahn ${ }^{1, *(D)}$ \\ 1 Department of Physics and Department of Energy Systems Research, Ajou University, Suwon 16499, Korea; \\ jhyim1977@gmail.com \\ 2 Panoptics Corp., Seongnam 13516, Korea; chem1225@panoptics.net (S.-y.K.); yskim@panoptics.net (Y.K.); \\ sycho@panoptics.net (S.C.); jskim@panoptics.net (J.K.) \\ * Correspondence: ahny@ajou.ac.kr
}

Citation: Yim, J.H.; Kim, S.-y.; Kim Y.; Cho, S.; Kim, J.; Ahn, Y.H. Rapid 3D-Imaging of Semiconductor Chips Using THz Time-of-Flight Technique. Appl. Sci. 2021, 11, 4770. https:// doi.org/10.3390/app11114770

Academic Editor: Akram Alomainy

Received: 15 April 2021

Accepted: 18 May 2021

Published: 22 May 2021

Publisher's Note: MDPI stays neutral with regard to jurisdictional claims in published maps and institutional affiliations.

Copyright: (c) 2021 by the authors. Licensee MDPI, Basel, Switzerland. This article is an open access article distributed under the terms and conditions of the Creative Commons Attribution (CC BY) license (https:// creativecommons.org/licenses/by/ $4.0 /)$.

\begin{abstract}
In this study, we developed a rapid three-dimensional (3D) time-of-flight imaging tool for inspection of packaged semiconductor chips, using terahertz $(\mathrm{THz})$ time-domain spectroscopy techniques. A high-speed THz system based on the optical sampling by cavity tuning technique is incorporated with a 2-axis galvano scanner to deliver a scanning speed of more than $100 \mathrm{~Hz} /$ pixel with a signal-to-noise ratio larger than $20 \mathrm{~dB}$. Through the use of the Hilbert transformation, we reconstruct the 3D structure of the packaged chip in a nondestructive manner. Additionally, the use of frequency-selective imaging allows us to manipulate image resolution; the higher resolution was obtained when monitored using the higher frequency component. Further, using phase information, we were able to detect and identify defects in the packaged chip, such as the delamination area and epoxy-rich regions.
\end{abstract}

Keywords: terahertz imaging; packaged chip; time-of-flight

\section{Introduction}

Terahertz (THz) spectroscopy has been widely adopted as a powerful tool for biomedical diagnosis, device inspection, and characterization of novel functional materials [1-6]. $\mathrm{THz}$ waves are transparent to nonconductive materials frequently used for the encapsulation of devices such as semiconducting chips; therefore, $\mathrm{THz}$ imaging allows us to characterize the internal structures of objects in a nondestructive manner [7-17]. Imaging using continuous-wave $(\mathrm{CW})$ sources has recently increased in popularity due to recent technological advances in the development of sources and detectors [18-22]; however, CW systems lack the ability to obtain three-dimensional (3D) tomographic information [23,24]. Although coherent THz tomography based on frequency-modulated CW (FMCW) methods have been developed using a tunable source or ensemble source, they are limited in terms of the depth and longitudinal resolution in general [25-27]. In contrast, the use of pulsed $\mathrm{THz}$ radiation from time-domain spectroscopy (TDS) enables the collection of information such as the depth and range of objects from reflected waves and the nature of scattering. In other words, THz pulsed imaging provides a direct 3D "map" of an object by using the time-of-flight (TOF) of the reflected $\mathrm{THz}$ pulses.

Although imaging using the THz-TDS system has numerous advantages, it suffers from low average source power and long acquisition time, making it unsuitable for many applications. As two-dimensional (2D) array detectors are not available, most THz TOF imaging systems require sample scanning, followed by reconstruction of a series of singlepoint measurements for reflected or transmitted waves. Additionally, the spectral resolution is linked to the inverse of the temporal window during the acquisition step, and there is a tradeoff between measurement time and spectral resolution. Novel THz-TDS systems were introduced commercially based on compact femtosecond fiber laser technology without the mechanical delay stage. For example, techniques such as electronically-controlled optical 
sampling (ECOPS), asynchronous optical sampling (ASOPS), and optical sampling by cavity tuning (OSCAT) deliver a rapid time delay of more than $100 \mathrm{~Hz}$ per scan with a wide temporal range (60 ps-10 ns) $[12,28,29]$. Recently, a novel 3D imaging technique based on the ECOPS system has been developed [12]. Artificial defects in glass fiber reinforced polymers have been imaged, proving their potential use for rapid, nondestructive inspection of various materials, components, and systems. However, a rapid imaging technique based on the galvano scanning system has not been introduced for inspection of defects in packaged chips, although packaged chips have been studied with the THz-TDS system using relatively slow sample scanning methods [3].

In this work, we report high-speed imaging for packaged integrated circuit (IC) inspection with a high temporal resolution based on the THz-TDS technique using the OSCAT system. We obtained nondestructive TOF images of IC chips, whose 3D information was analyzed with respect to both the temporal and spectral domains. Further, the reconstruction of the 3D plots allows us to identify defects in the packaging, which is not possible using 2D integrated images.

\section{Experimental Setup}

A schematic and a photograph of the $\mathrm{THz}$ TOF imaging equipment are illustrated in Figure $1 \mathrm{a}, \mathrm{b}$, respectively. For the rapid THz-TDS system, we used a commercialized OSCAT (TERA-OSCAT, MenloSystems GmbH), which allows for a speed of 100-200 Hz/pixel. Therefore, a measurement time of less than $10 \mathrm{~s}$ is allowed for each image, with a pixel number of $32 \times 32$ pixels. We incorporated a 2D galvano scanner (Hurryscan25, SCANLAB $\mathrm{GmbH}$ ), enabling us to obtain the images with a speed that is limited by the OSCAT $\mathrm{THz}-\mathrm{TDS}$ system. The THz signal (with a beam size of $2 \mathrm{~cm}$ after the collimation lens) was focused using either a customized f-theta lens (Teflon) or a convex lens, both with a focal length of $5 \mathrm{~cm}$ and a diameter of $3.8 \mathrm{~cm}$. The reflected $\mathrm{THz}$ signal was collected using a 50:50 beamsplitter (Tydex Inc., St. Petersburg, Russia), which was fed into the THz receiving antenna (denoted by $\mathrm{Rx}$ ). The current signal from the antenna was amplified using a fast current preamplifier (DLPCA-100; FEMTO Messtechnik $\mathrm{GmbH}$ ) and digitized with a conventional data acquisition card. The collected data contain the phase-sensitive $\mathrm{THz}$ amplitudes as a function of the 3D parameters such as the time delay, $x$-axis, and $y$-axis. They are recorded as a single binary file, which can be reconstructed using home-built analyzing software.

Figure 1c shows a representative $\mathrm{THz}$ TOF signal (A-scan) where the focused $\mathrm{THz}$ beam is reflected on one of the encapsulated IC chips. The signal-to-noise ratio reached $20 \mathrm{~dB}$ at a rate of $100 \mathrm{~Hz}$. Clearly, we can identify the multiple pulsed signals reflected from the front of the sample, the IC chip, and the back plane of the sample, which will be shown in more detail later. We note that the thickness of the beamsplitter was $5 \mathrm{~mm}$; hence, there was no noticeable multiple reflection effect from the beamsplitter. Here, the time delay can be converted into depth information, in which 1 ps corresponds to $0.15 / \mathrm{n} \mathrm{mm}$, where $\mathrm{n}$ is the refractive index of the materials. The refractive index of the encapsulating material was about 2.0 for all chips used in the experiment. 


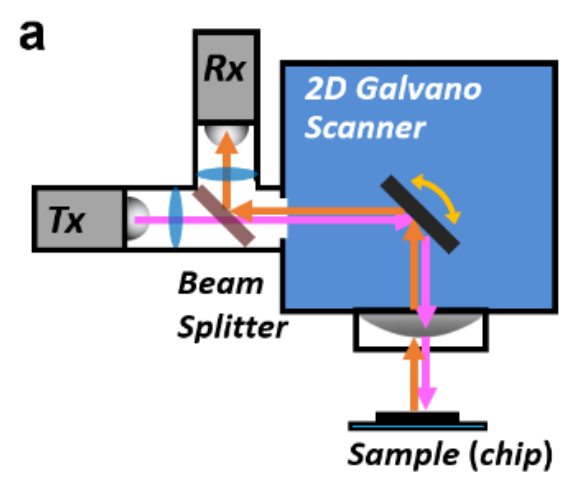

b
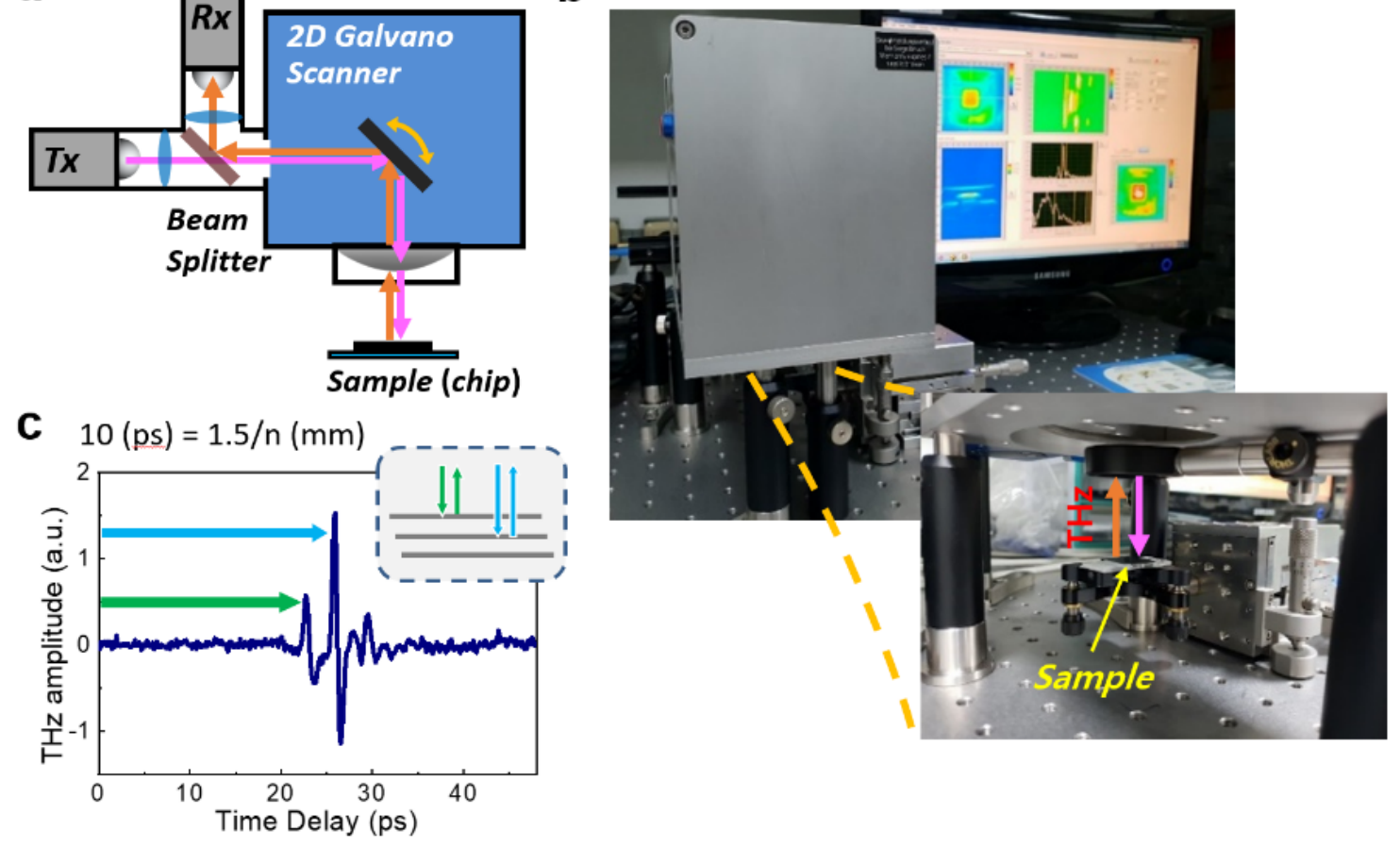

Figure 1. (a) A schematic illustration of THz TOF imaging equipment. (b) Photograph of the experimental setup. (c) A representative $\mathrm{THz}$ waveform in the time-domain (A-scan) reflected from a packaged chip.

\section{Results and Discussion}

Figure 2a shows the THz TOF imaging result of a packaged chip with dimensions $12.0 \mathrm{~mm} \times 20.25 \mathrm{~mm} \times 1.0 \mathrm{~mm}$. Figure $2 \mathrm{~b}$ shows the time-integrated C-scan data (plotted as a function of the $x$ - and $y$-axis), in which the THz envelope signal (obtained via the Hilbert transformation) was time-integrated each pixel. In other words, the envelope signal was achieved from the complex $\mathrm{THz}$ signal $\widetilde{E}_{\mathrm{THz}}=\operatorname{Re}\left(\widetilde{E}_{\mathrm{THz}}\right)+i H\left[\operatorname{Re}\left(\widetilde{E}_{\mathrm{THz}}\right)\right]$, where $H$ is the Hilbert transformation [30]. The scan range was $22 \times 22 \mathrm{~mm}^{2}$, and the pixel size was $100 \times 100 \mathrm{pxl}^{2}$. The bright square in the lower middle region indicates the semiconducting chip embedded in the package, with a size of $5 \mathrm{~mm} \times 3 \mathrm{~mm}$. As mentioned previously, $\mathrm{THz}$ imaging is a powerful tool for nondestructive mapping of objects such as semiconductor chips embedded in nonconductive envelopes. However, the THz-TDS system has rarely been used for semiconducting analysis, especially with imaging speeds higher than $100 \mathrm{~Hz}$ /pixel. Thus, THz-TDS allows us to address the depth profiling of the packaged devices displayed as B-scan results in Figure 2c,d. In other words, in Figure 2c, the THz signal was plotted as a function of the position $\mathrm{x}$ (along the horizontal dashed line in Figure 2b) and time-delay (T). Another B-scan image (Figure 2d) taken along the vertical dashed line in Figure $2 b$ shows similar results, with the chip location clearly displayed. It should be noted that the $\mathrm{THz}$ reflection signal beneath the chip area is suppressed significantly as most of the signal is reflected by the chip.

There are multiple approaches for analyzing image data according to the application. Figure 3 shows a series of C-scan images for different $\mathrm{z}$ locations for the sample shown in Figure 2. Figure 3a-c show THz reflection images at top, chip, and bottom surfaces appeared at $\mathrm{T}=22.7 \mathrm{ps}, 25.9 \mathrm{ps}$, and $29.5 \mathrm{ps}$, respectively. Considering the refractive index of the packaging material $(n=2.0)$, the TOF time differences reveal that the chip surface is located at $0.24 \mathrm{~mm}(\Delta \mathrm{T}=3.2 \mathrm{ps})$ beneath the package surface. Conversely, the bottom surface appeared at $0.5 \mathrm{~mm}(\Delta \mathrm{T}=6.8 \mathrm{ps})$. We note that $\mathrm{THz}$ reflection at the other side of the package surface (located at $1 \mathrm{~mm}$ beneath the top surface) is very weak as it appeared at T $\sim 36 \mathrm{ps}$ in Figure 2c,d. Consequently, the THz TOF data can then be reconstructed into 3D images, as shown in Figure 3d. Here, different colors were assigned for the structures 
located at different heights, with red indicating the position of the chip. In this regard, $3 \mathrm{D}$ imaging could potentially be very effective in locating defects, a task that is virtually impossible using 2D section images.
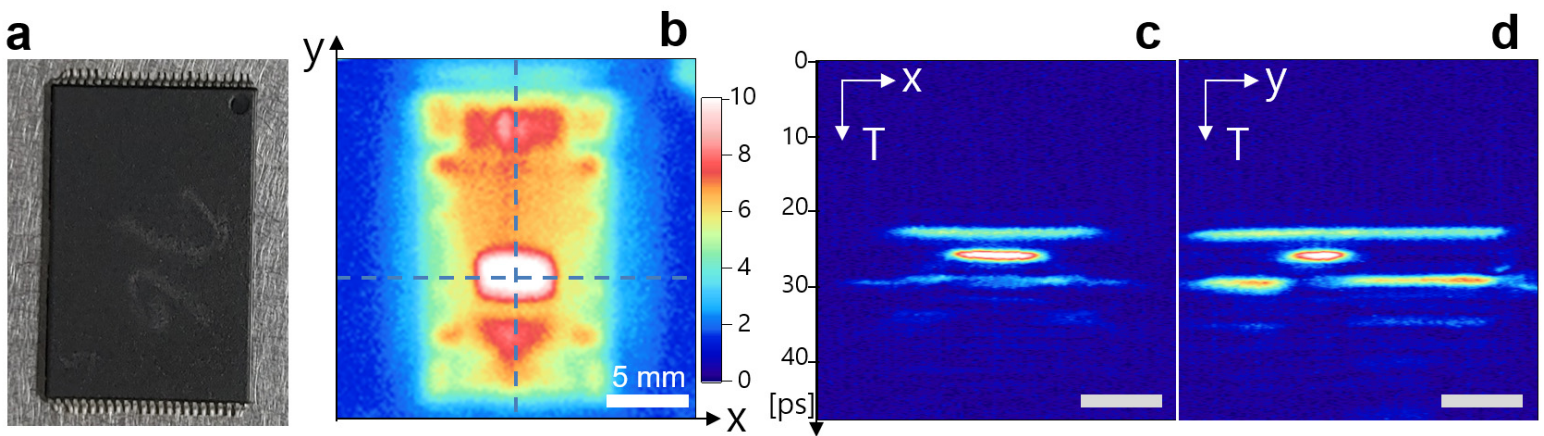

Figure 2. (a) A photograph of packaged chip. (b) The time-integrated C-scan image (in terms of envelop function) for (a). $(\mathbf{c}, \mathbf{d})$ Cross-sectional B-scan images along with the $x$-axis and $y$-axis taken from $(\mathbf{b})$. (See dashed lines in (b)).
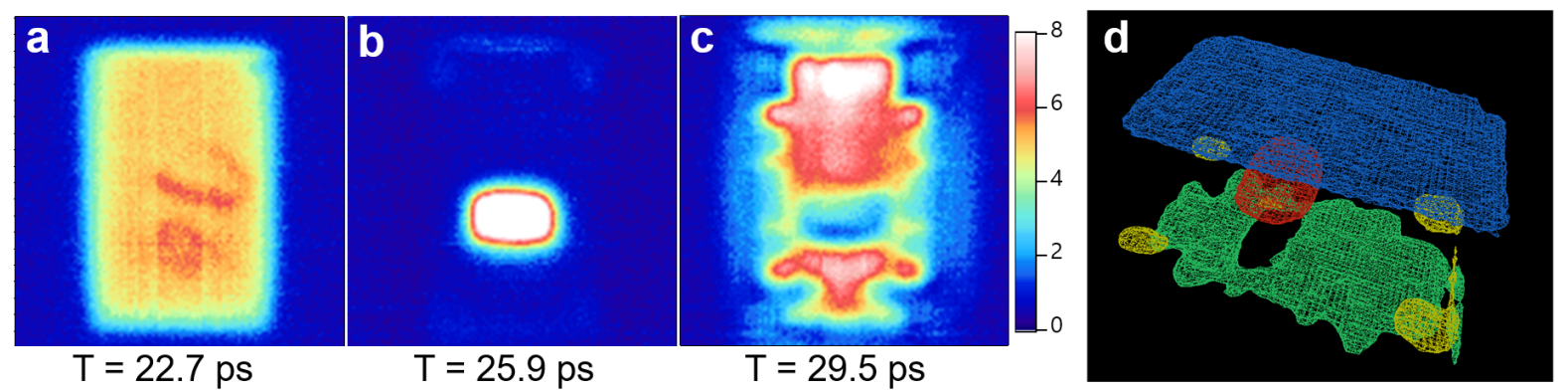

Figure 3. C-scan images of top (a), chip (b), and bottom (c) surfaces. (d) A reconstructed 3D image of the sample.

A Fourier transformation of $\mathrm{THz}$ amplitudes recorded using TDS spectroscopy allowed for inspection of the sample at specific spectral ranges. Figure 4a shows the spectrum of the reflected signal when the THz beam and the chip share a position. The oscillatory pattern is due to interference between different layers. A series of C-scan images are shown in Figure $4 \mathrm{~b}-\mathrm{d}$, for the frequencies of $0.4 \mathrm{THz}, 0.7 \mathrm{THz}$, and $1.0 \mathrm{THz}$, respectively. The transverse resolution was improved dramatically as we employed the high-frequency components, although the signal strength decreases with increasing frequency (from $1.8 \mathrm{~mm}$ at $0.4 \mathrm{THz}$ to $700 \mu \mathrm{m}$ at $1.0 \mathrm{THz}$.) Therefore, it is desirable to develop $\mathrm{THz}$ sources with higher frequency ranges to identify the defects with a better transverse and longitudinal resolution for practical application in the industry. We also note that the interference effect significantly modifies image contrast, which could offer an additional degree of freedom in regard to analyzing $\mathrm{THz}$ images for various applications; this necessitates future investigation.

Finally, we show an example of the identification of defect types in the packaged chips. Figure 5a shows a photograph of a semiconductor package with dimensions $12 \mathrm{~mm}$ $\times 8 \mathrm{~mm} \times 1 \mathrm{~mm}$. Figure $5 \mathrm{~b}, \mathrm{c}$ show 3D images of the two different samples. Here, the white layer indicates the reflection from the front surface of packaged chip, whereas the red layer corresponds to that of the chip surface. The sample shown in Figure $5 \mathrm{~b}$ exhibits a relatively uniform reflection from both the front and chip layers. In contrast, in Figure 5c, the reflected signals from some areas of the chip surface were suppressed significantly, which is also shown by the time-integrated C-scan image in Figure 5d. To unravel the signal origin, Figure 5e shows a B-scan image (in terms of envelope function), taken along the dashed line in Figure 5d. The signal is suppressed in the region indicated by the dashed rectangle, although it is still strong enough to reveal that the signal has a multiple reflection feature with a time difference of $\Delta \mathrm{T}=1.56 \mathrm{ps}$. This indicates the presence of a gap between the plastic packaging and the chip. 

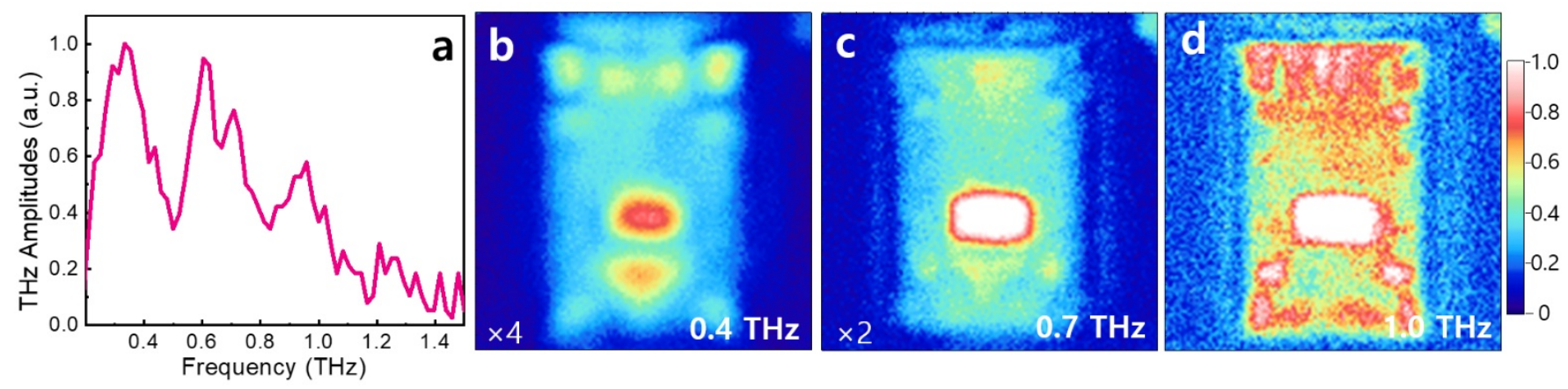

Figure 4. (a) The spectrum of the reflected $\mathrm{THz}$ pulses from the chip position. (b-d) A series of C-scan images for the frequencies of $0.4 \mathrm{THz}(\mathbf{b}), 0.7 \mathrm{THz}(\mathbf{c})$, and $1.0 \mathrm{THz}(\mathbf{d})$.

a
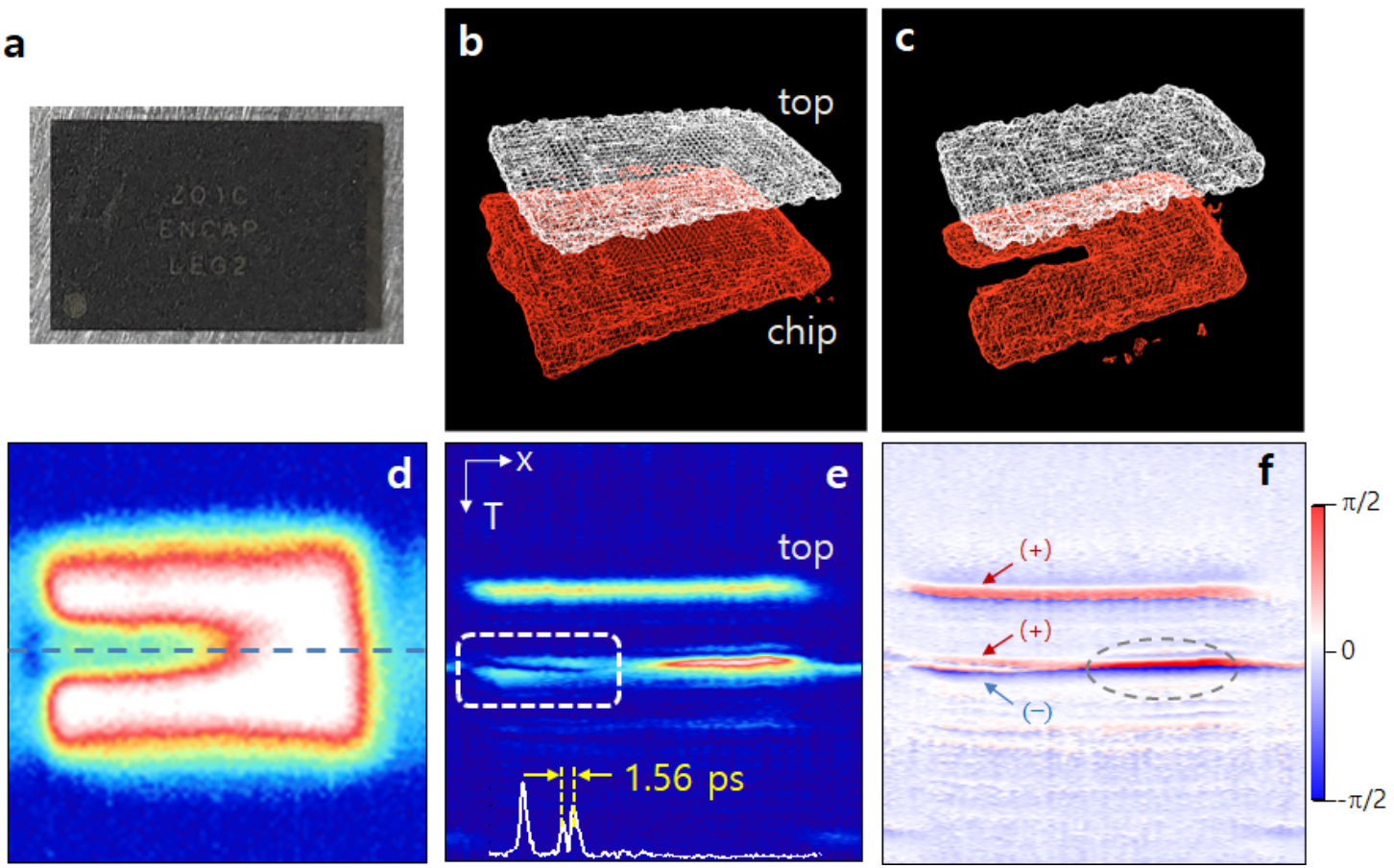

Figure 5. A photograph of the packaged chip (a), including a comparison of 3D images between a normal sample (b) and one with defects (c). (d-f) Time-integrated C-scan (d), B-scan in terms of envelop function (e), and B-scan in terms of phase function (f) images of the sample shown in (c).

We also found that phase information is crucial in deciding defect type, i.e., whether the void area is due to delamination or the epoxy-rich region. This is a very important issue to address because reliable mechanical support for the packaged chip is essential for the physical protection of the device, distribution of electrical power, and heat dissipation of circuits [31]. In Figure 5f, we show the B-scan image in terms of the phase function obtained through the use of the Hilbert transformation. Here, the positive (negative) phase indicates the reflection at surfaces with the higher (lower)-indexed medium. Therefore, the reflection with the positive phase in the upper layer (red arrow) and the negative phase in the bottom layer (blue arrow) indicates that the gap is filled with dielectric material (i.e., epoxy) with a higher index than that of the plastic packaging. It is also consistent with the fact that the signal is suppressed significantly because the epoxy resin material has absorptive qualities [32,33]. Further, we note that the region indicated by a dashed circle in Figure $5 \mathrm{f}$ shows both positive and negative phases, implying that there is an epoxy layer between the molding plastic and the chip, even though they are too close to be resolved by our system. In other words, THz TOF imaging with a phase analysis is a powerful tool for 
identifying types of defects, such as delamination, which is critical in the reliability of the packaged chips.

\section{Conclusions}

In conclusion, we developed a rapid 3D TOF imaging tool for the inspection of packaged semiconductor chips using the time-domain $\mathrm{THz}$ spectroscopy technique. The OSCAT system was incorporated with a 2-axis galvano scanner to deliver a scanning speed of more than $100 \mathrm{~Hz}$ /pixel with a signal-to-noise ratio larger than $20 \mathrm{~dB}$. Through the use of the Hilbert transformation, we could clearly reconstruct the 3D structure of the packaged chip in a nondestructive manner. Conversely, frequency-selective imaging allowed us to manipulate the resolution of the images, and we found that higher resolution was obtained when monitored with the higher frequency component. Importantly, phase information could be used to reveal the presence and types of defects in the packaged chip, such as delamination and the presence of epoxy-rich regions. Our work will contribute to the development of in-line inspection methodology in the industry, such as semiconducting, biomedical, and novel functional material characterization.

Author Contributions: Conceptualization, Y.H.A.; Funding acquisition, S.-y.K., Y.K., S.C. and J.K.; Investigation, J.H.Y. and Y.H.A.; Methodology, Y.H.A.; Project administration, J.K.; Writing-original draft, J.H.Y. and Y.H.A.; Writing-review and editing, S.-y.K., Y.K., S.C. and J.K. All authors have read and agreed to the published version of the manuscript.

Funding: This work was supported by the Midcareer Researcher Program (2020R1A2C1005735) through a National Research Foundation grant funded by the Korean Government and by the Human Resources Program in Energy Technology (20184030202220) of the Korea Institute of Energy Technology Evaluation and Planning (KETEP) grant funded by the Korean Government.

Institutional Review Board Statement: Not applicable.

Informed Consent Statement: Not applicable.

Data Availability Statement: Data is contained within the article.

Conflicts of Interest: The authors declare no conflict of interest.

\section{References}

1. Ogawa, Y.; Hayashi, S.I.; Oikawa, M.; Otani, C.; Kawase, K. Interference terahertz label-free imaging for protein detection on a membrane. Opt. Express 2008, 16, 22083-22089. [CrossRef] [PubMed]

2. Tomaino, J.L.; Jameson, A.D.; Paul, M.J.; Kevek, J.W.; van der Zande, A.M.; Barton, R.A.; Choi, H.; McEuen, P.L.; Minot, E.D.; Lee, Y.-S. High-Contrast Imaging of Graphene via Time-Domain Terahertz Spectroscopy. J. Infrared Millim. Terahertz Waves 2012, 33, 839-845. [CrossRef]

3. Park, S.-H.; Jang, J.-W.; Kim, H.-S. Non-destructive evaluation of the hidden voids in integrated circuit packages using terahertz time-domain spectroscopy. J. Micromech. Microeng. 2015, 25, 095007. [CrossRef]

4. Zhong, S.; Shen, Y.-C.; Ho, L.; May, R.K.; Zeitler, J.A.; Evans, M.; Taday, P.F.; Pepper, M.; Rades, T.; Gordon, K.C.; et al. Nondestructive quantification of pharmaceutical tablet coatings using terahertz pulsed imaging and optical coherence tomography. Opt. Lasers Eng. 2011, 49, 361-365. [CrossRef]

5. Park, S.J.; Hong, J.T.; Choi, S.J.; Kim, H.S.; Park, W.K.; Han, S.T.; Park, J.Y.; Lee, S.; Kim, D.S.; Ahn, Y.H. Detection of microorganisms using terahertz metamaterials. Sci. Rep. 2014, 4, 4988. [CrossRef] [PubMed]

6. Kim, H.S.; Ha, N.Y.; Park, J.-Y.; Lee, S.; Kim, D.-S.; Ahn, Y.H. Phonon-Polaritons in Lead Halide Perovskite Film Hybridized with THz Metamaterials. Nano Lett. 2020, 20, 6690-6696. [CrossRef] [PubMed]

7. Ahi, K.; Shahbazmohamadi, S.; Asadizanjani, N. Quality control and authentication of packaged integrated circuits using enhanced-spatial-resolution terahertz time-domain spectroscopy and imaging. Opt. Lasers Eng. 2018, 104, 274-284. [CrossRef]

8. Federici, J.F.; Schulkin, B.; Huang, F.; Gary, D.; Barat, R.; Oliveira, F.; Zimdars, D. THz imaging and sensing for security applications-explosives, weapons and drugs. Semicond. Sci. Technol. 2005, 20, S266-S280. [CrossRef]

9. Shen, Y.C.; Lo, T.; Taday, P.F.; Cole, B.E.; Tribe, W.R.; Kemp, M.C. Detection and identification of explosives using terahertz pulsed spectroscopic imaging. Appl. Phys. Lett. 2005, 86, 241116. [CrossRef]

10. Fan, S.; Li, T.; Zhou, J.; Liu, X.; Liu, X.; Qi, H.; Mu, Z. Terahertz non-destructive imaging of cracks and cracking in structures of cement-based materials. Aip Adv. 2017, 7, 115202. [CrossRef]

11. Hua, Z.; Jingzhou, X.; Xu, X.; Tao, Y.; Reightler, R.; Madaras, E.; Xi-Cheng, Z. Nondestructive defect identification with terahertz time-of-flight tomography. IEEE Sens. J. 2005, 5, 203-208. [CrossRef] 
12. Jin, K.H.; Kim, Y.-G.; Cho, S.H.; Ye, J.C.; Yee, D.-S. High-speed terahertz reflection three-dimensional imaging for nondestructive evaluation. Opt. Express 2012, 20, 25432-25440. [CrossRef]

13. Karpowicz, N.; Redo, A.; Hua, Z.; Xia, L.; Jingzhou, X.; Zhang, X.C. Continuous-Wave Terahertz Imaging for Non-Destructive Testing Applications. In Proceedings of the 2005 Joint 30th International Conference on Infrared and Millimeter Waves and 13th International Conference on Terahertz Electronics, Williamsburg, VA, USA, 19-23 September 2005; Volume 321, pp. 329-330.

14. Kawase, K.; Ogawa, Y.; Watanabe, Y.; Inoue, H. Non-destructive terahertz imaging of illicit drugs using spectral fingerprints. Opt. Express 2003, 11, 2549-2554. [CrossRef]

15. Kawase, K.; Shibuya, T.; Hayashi, S.i.; Suizu, K. THz imaging techniques for nondestructive inspections. Comptes Rendus Phys. 2010, 11, 510-518. [CrossRef]

16. Schirmer, M.; Fujio, M.; Minami, M.; Miura, J.; Araki, T.; Yasui, T. Biomedical applications of a real-time terahertz color scanner. Biomed. Opt. Express 2010, 1, 354-366. [CrossRef] [PubMed]

17. Zhang, J.-Y.; Ren, J.-J.; Li, L.-J.; Gu, J.; Zhang, D.-D. THz imaging technique for nondestructive analysis of debonding defects in ceramic matrix composites based on multiple echoes and feature fusion. Opt. Express 2020, 28, 19901-19915. [CrossRef] [PubMed]

18. Lien Nguyen, K.; Johns, M.L.; Gladden, L.F.; Worrall, C.H.; Alexander, P.; Beere, H.E.; Pepper, M.; Ritchie, D.A.; Alton, J.; Barbieri, S.; et al. Three-dimensional imaging with a terahertz quantum cascade laser. Opt. Express 2006, 14, 2123-2129. [CrossRef]

19. Karpowicz, N.; Zhong, H.; Xu, J.; Lin, K.-I.; Hwang, J.-S.; Zhang, X.C. Comparison between pulsed terahertz time-domain imaging and continuous wave terahertz imaging. Semicond. Sci. Technol. 2005, 20, S293-S299. [CrossRef]

20. Ok, G.; Park, K.; Kim, H.J.; Chun, H.S.; Choi, S.-W. High-speed terahertz imaging toward food quality inspection. Appl. Opt. 2014, 53, 1406-1412. [CrossRef]

21. Karpowicz, N.; Zhong, H.; Zhang, C.; Lin, K.-I.; Hwang, J.-S.; Xu, J.; Zhang, X.-C. Compact continuous-wave subterahertz system for inspection applications. Appl. Phys. Lett. 2005, 86, 054105. [CrossRef]

22. Lee, I.-S.; Lee, J.W. Nondestructive Internal Defect Detection Using a CW-THz Imaging System in XLPE for Power Cable Insulation. Appl. Sci. 2020, 10, 2055. [CrossRef]

23. Kim, J.-Y.; Song, H.-J.; Yaita, M.; Hirata, A.; Ajito, K. CW-THz vector spectroscopy and imaging system based on 1.55- $\mu$ m fiber-optics. Opt. Express 2014, 22, 1735-1741. [CrossRef] [PubMed]

24. Moon, K.; Lee, I.-M.; Lee, E.S.; Park, K.H. Photonics-Based Multi-Spectral THz Imaging Using a Dual-Mode Laser and a Telecentric f- $\theta$ Lens. In Proceedings of the Conference on Lasers and Electro-Optics, San Jose, CA, USA, 5 May 2019; p. STu3F.7.

25. Nagatsuma, T.; Nishii, H.; Ikeo, T. Terahertz imaging based on optical coherence tomography [Invited]. Photon. Res. 2014, 2, B64-B69. [CrossRef]

26. Cristofani, E.; Friederich, F.; Wohnsiedler, S.; Matheis, C.; Jonuscheit, J.; Vandewal, M.; Beigang, R. Nondestructive testing potential evaluation of a terahertz frequency-modulated continuous-wave imager for composite materials inspection. Opt. Eng. 2014, 53, 031211. [CrossRef]

27. Yahng, J.S.; Park, C.-S.; Don Lee, H.; Kim, C.-S.; Yee, D.-S. High-speed frequency-domain terahertz coherence tomography. Opt Express 2016, 24, 1053-1061. [CrossRef]

28. Bartels, A.; Cerna, R.; Kistner, C.; Thoma, A.; Hudert, F.; Janke, C.; Dekorsy, T. Ultrafast time-domain spectroscopy based on high-speed asynchronous optical sampling. Rev. Sci. Instrum. 2007, 78, 035107. [CrossRef]

29. Wilk, R.; Hochrein, T.; Koch, M.; Mei, M.; Holzwarth, R. OSCAT: Novel Technique for Time-Resolved Experiments without Moveable Optical Delay Lines. J. Infrared Millim. Terahertz Waves 2011, 32, 596-602. [CrossRef]

30. Kong, D.-Y.; Wu, X.-J.; Wang, B.; Gao, Y.; Dai, J.; Wang, L.; Ruan, C.-J.; Miao, J.-G. High resolution continuous wave terahertz spectroscopy on solid-state samples with coherent detection. Opt. Express 2018, 26, 17964-17976. [CrossRef]

31. Lei, W.-S.; Kumar, A. Delamination and Reliability Issues in Packaged Devices. In Adhesion in Microelectronics; John Wiley \& Sons: Hoboken, NJ, USA, 2014; pp. 267-312.

32. Piesiewicz, R.; Jansen, C.; Wietzke, S.; Mittleman, D.; Koch, M.; Kürner, T. Properties of Building and Plastic Materials in the THz Range. Int. J. Infrared Millim. Waves 2007, 28, 363-371. [CrossRef]

33. Stübling, E.; Gomell, L.; Sommer, S.; Winkel, A.; Kahlmeyer, M.; Böhm, S.; Koch, M. THz Properties of Adhesives. J. Infrared Millim. Terahertz Waves 2018, 39, 586-593. [CrossRef] 